\title{
Preparation, structural, Raman and impedance spectroscopic characterisation of the silver ion conductor $(\mathrm{AgI})_{2} \mathrm{Ag}_{3} \mathrm{SbS}_{3} \dagger \ddagger$
}

\author{
Tom Nilges, ${ }^{a}$ Sara Reiser, ${ }^{a}$ Jung Hoon Hong, ${ }^{a}$ Etienne Gaudin ${ }^{b}$ and Arno Pfitzner ${ }^{a}$ \\ a Institut für Anorganische Chemie, Universität Regensburg, 93040, Regensburg, Germany. \\ E-mail: arno.pfitzner@chemie.uni-regensburg.de; Fax: +49 941943 4983; \\ Tel: +499419434551 \\ ${ }^{b}$ ICMCB - CNRS, 87, Avenue du Docteur Schweitzer, 33608, PESSAC cedex, France. \\ E-mail: gaudin@icmcb.u-bordeaux.fr; Fax: +33 5568427 61; Tel: +33 556846328
}

\author{
Received 12th April 2002, Revised 26th September 2002 \\ First published as an Advance Article on the web 30th October 2002
}

\begin{abstract}
Pale yellow $(\mathrm{AgI})_{2} \mathrm{Ag}_{3} \mathrm{SbS}_{3}$ was synthesized by the reaction of stoichiometric amounts of $\mathrm{AgI}$ and $\mathrm{Ag}_{3} \mathrm{SbS}_{3}$ $(2: 1)$ at $683 \mathrm{~K}$. It is air stable for several months. The crystal structure was determined at different temperatures in the range from $173 \mathrm{~K}$ to $573 \mathrm{~K}$ by single crystal X-ray diffraction. $(\mathrm{AgI})_{2} \mathrm{Ag}_{3} \mathrm{SbS}_{3}$ crystallizes in the orthorhombic system, space group Pnnm (no. 58) with $a=10.9674(8) \AA, b=13.5200(12) \AA, c=7.7460(5) \AA$, $V=1156.3(5) \AA^{3}$, and $Z=4$ (data at $298 \mathrm{~K}$ ). The title compound is isotypic with $(\mathrm{CuI})_{2} \mathrm{Cu}_{3} \mathrm{SbS}_{3}$, at least for the positions of $\mathrm{I}, \mathrm{Sb}$, and $\mathrm{S}$. The silver atoms are highly disordered and therefore their displacement parameters were refined using a Gram-Charlier non-harmonic development. No phase transition is observed between $173 \mathrm{~K}$ and the melting point at $720 \mathrm{~K}$ (DSC, onset temperature). The distribution of silver changes drastically with temperature and the localization of silver increases at low temperature. A high ionic conductivity is observed in combination with a pronounced disorder of the silver atoms. Impedance spectroscopic measurements reveal specific conductivity data of $\sigma=8.15 \times 10^{-5} \Omega^{-1} \mathrm{~cm}^{-1}$ at $332 \mathrm{~K}$ and of $\sigma=1.52 \times 10^{-3}$ $\Omega^{-1} \mathrm{~cm}^{-1}$ at $478 \mathrm{~K}$. The activation energy is $E_{A}=0.29 \mathrm{eV}$. Raman spectra are dominated by the stretching modes of the $\left[\mathrm{SbS}_{3}\right]^{3-}$ units at 357,327 and $316 \mathrm{~cm}^{-1}$ at room temperature.
\end{abstract}

\section{Introduction}

Due to their multiple applications numerous efforts have been made in the past to synthesize new ion conducting materials with both optimized conductivity and chemical stability. Proton, lithium, and silver ion conductors are of special interest among various cation conducting materials. We recently started a systematic exploration of a series of new copper ion conducting materials in order to determine the influence of various structural and chemical parameters on the ion mobility in the solid state. It turned out that adducts of copper halides to neutral molecules of group 15 or group 16 elements, e.g. $(\mathrm{CuI})_{3} \mathrm{P}_{12}{ }^{1}$ or $(\mathrm{CuBr}) \mathrm{Te},{ }^{2}$ can be regarded as a new class of copper ion conducting materials. ${ }^{3,}{ }^{4}$ However, the use of copper(I) halides as a preparative tool for the synthesis of new neutral main group molecules does not provide optimized ionic conductors. ${ }^{5}$ If copper is embedded in a pure anionic environment instead of anions and neutral ligands the ionic conductivity is expected to increase significantly due to enhanced polarisability of the anions. Whereas no mixed copper chalcogenide halides are known to date, the combination of copper halides with copper thiometallates, that is, compounds

$\dagger$ Part of these results were presented at the 79th International Bunsen Discussion Meeting of the Deutsche Bunsen-Gesellschaft für Physikalische Chemie, Münster, Germany, October 10-12, 2001.

$\ddagger$ Electronic supplementary information (ESI) available: joint probability density functions, anisotropic displacement parameters and selected interatomic distances. Crystallographic data (single crystal data) in cif format (ICSD reference numbers CSD-412485 $(T=173 \mathrm{~K})$, CSD-412486 $(T=298 \mathrm{~K}), \operatorname{CSD}-412487(T=373 \mathrm{~K})$, CSD-412488 $(T=423 \mathrm{~K}), \mathrm{CSD}-412489(T=473 \mathrm{~K})$, CSD-412490 $(T=523 \mathrm{~K})$, CSD-412491 $(T=573 \mathrm{~K}))$. See http://www.rsc.org/ suppdata/cp/b2/b203556a/ containing complex thioanions e.g. of $\mathrm{Sb}^{3+}$ or $\mathrm{Te}^{4+}$, provides new copper ion conductors which can be regarded as composite materials. $(\mathrm{CuI})_{2} \mathrm{Cu}_{3} \mathrm{SbS}_{3}{ }^{6}$ and $(\mathrm{CuI})_{3} \mathrm{Cu}_{2} \mathrm{TeS}_{3}{ }^{7}$ exhibit an enhanced ionic conductivity combined with a comparably small activation energy even in the room temperature (RT) region. ${ }^{8}$ By contrast, $\mathrm{CuClCu}_{2} \mathrm{TeS}_{3}$ can be regarded as mainly semiconducting. ${ }^{8,9}$ We have recently started to transfer the findings concerning the copper ion conductors to homologous silver and lithium compounds. Since only a little knowledge exists about mixed chalcogenide halides of these two elements one might expect a progress in the development of new ion conducting quaternary composites. $\mathrm{Ag}_{3} \mathrm{SX}(\mathrm{X}=\mathrm{I}, \mathrm{Br}),{ }^{10,11}$ argyrodite-type compounds, e.g. $\mathrm{Ag}_{7} \mathrm{GeS}_{5} \mathrm{I}^{12}$ and $\mathrm{AgIn}_{2} \mathrm{X}_{3} \mathrm{Y}$ $(\mathrm{X}=\mathrm{S}, \mathrm{Se}, \mathrm{Te}, \mathrm{Y}=\mathrm{Cl}, \mathrm{Br}, \mathrm{I})^{13}$ are examples of mixed silver chalcogenide halides. Another example for a mixed chalcogenide halide of silver is the compound $\mathrm{Ag}_{5} \mathrm{Te}_{2} \mathrm{Cl}^{14}$ This compound shows an enhanced silver ion conductivity accompanied with several phase transitions. ${ }^{15}$ Herein we report the synthesis and characterization of $(\mathrm{AgI})_{2} \mathrm{Ag}_{3} \mathrm{SbS}_{3}$ which is closely related to $(\mathrm{CuI})_{2} \mathrm{Cu}_{3} \mathrm{SbS}_{3}$. Structural aspects and ionic pathways will be discussed with respect to the ionic conductivity.

\section{Experimental details}

$(\mathrm{AgI})_{2} \mathrm{Ag}_{3} \mathrm{SbS}_{3}$ was prepared by the reaction of $\mathrm{AgI}(99.9 \%$, Alfa), and $\mathrm{Ag}_{3} \mathrm{SbS}_{3}$ in the ratio 2:1 in evacuated silica ampoules. $\mathrm{Ag}_{3} \mathrm{SbS}_{3}$ was prepared from the elements (Ag, 99.9\%, Ventron, Sb, 99.999\%, Heraeus, S, 99.999\%, Fluka) at $823 \mathrm{~K}$. The homogenized starting materials were fused at $873 \mathrm{~K}$. After cooling to room temperature the yellow reaction product was homogenized and then annealed at $683 \mathrm{~K}$ for 4 weeks. Single crystals of suitable size for a single crystal 
X-ray structure determination could be separated from the pure, pale yellow microcrystalline reaction product. $(\mathrm{AgI})_{2} \mathrm{Ag}_{3} \mathrm{SbS}_{3}$ is neither air nor moisture sensitive over a period of several months. The reaction product was characterized by X-ray powder techniques (Siemens D5000, $\mathrm{Cu} \mathrm{K} \alpha_{1}$, $\lambda=1.54051 \AA$, Si as an external standard), vide infra for crystallographic data. Differential thermal analysis (DSC) measurements (DSC7, Perkin-Elmer) showed that $(\mathrm{AgI})_{2} \mathrm{Ag}_{3} \mathrm{SbS}_{3}$ melts at $720 \mathrm{~K}\left(\Delta H_{\text {fus }}=64.8 \mathrm{~J} \mathrm{~g}^{-1}\right)$ without decomposition. Impedance spectroscopic investigations were performed in the frequency range $100 \mathrm{mHz}-4 \mathrm{MHz}$ (IM6, Zahner Elektrik). Pressed powder samples of the title compound were contacted between gold electrodes, details of the experimental setup are given elsewhere. ${ }^{3}$ Raman spectra of the title compound were recorded with a RFS100/S (BRUKER) in a backscattering mode using a Nd:YAG laser with an excitation wavelength of $1064 \mathrm{~nm}$.

\section{Results and discussion}

\section{Temperature dependent structure determination}

Structure refinement including a non-harmonic approach. The crystal structure of $(\mathrm{AgI})_{2} \mathrm{Ag}_{3} \mathrm{SbS}_{3}$ was determined from single crystals of suitable size $\left(0.26 \times 0.18 \times 0.06 \mathrm{~mm}^{3}\right.$ (low temperature $(\mathrm{LT})), \quad 0.16 \times 0.20 \times 0.31$ (high temperature $(\mathrm{HT})))$ at temperatures between $173 \mathrm{~K}$ and $573 \mathrm{~K}$. The crystals were glued on a glass capillary and mounted on an IPDS (Stoe) single crystal diffractometer providing monochromatic Mo $\mathrm{K} \alpha$ radiation $(\lambda=0.71073 \AA$ ). An Oxford cryostream cooling device for the LT and a Stoe heating device for the HT measurements was used for the temperature dependent diffraction data collection. Lattice constants were derived and refined from the positions of 8000 reflections. Crystallographic data are summarized in Table 1 . The space group Pnnm which was already determined for $(\mathrm{CuI})_{2} \mathrm{Cu}_{3} \mathrm{SbS}_{3}$ was derived from the systematic extinctions. All data were corrected for Lorentz and polarization effects. Absorption was corrected numerically and the description of the crystal shape was optimized with the $\mathrm{X}_{-\mathrm{SHAPE}}{ }^{16}$ routine. The positions of $(\mathrm{CuI})_{2} \mathrm{Cu}_{3} \mathrm{SbS}_{3}$ were taken as a starting point for the refinement of the RT data set with silver located on the copper positions. With fully occupied positions and anisotropic atomic displacement parameters (ADPs) the refinement converged to $R=0.066(\mathrm{w} R=0.095)$ for 67 parameters. At this step of the refinement the silver positions exhibit strong ADP values. This suggests a pronounced disorder of silver in the framework of thioantimonate and iodide ions. A non-harmonic development of the silver ADPs up to the fourth order was first tested analogous to $(\mathrm{CuI})_{2}$ $\mathrm{Cu}_{3} \mathrm{SbS}_{3} .{ }^{6} \mathrm{~A}$ detailed description of the non-harmonic approach is given there as well. This model lowered the $R$ value significantly. A combination of a split model and a non-harmonic development of the silver ADPs was finally used because of the pronounced deformation. A reduction of the number of refineable parameters was also achieved by this approach. With a splitting of the $\mathrm{Ag} 2, \mathrm{Ag} 3$, and $\mathrm{Ag} 4$ positions and non-harmonic ADPs up to the third order for the Ag1, $\mathrm{Ag} 2, \mathrm{Ag} 3$, and $\mathrm{Ag} 4$ positions the refinement converged to

Table 1 Selected crystallographic data of $(\mathrm{AgI})_{2} \mathrm{Ag}_{3} \mathrm{SbS}_{3}$

\begin{tabular}{|c|c|c|c|c|c|c|c|}
\hline & $173 \mathrm{~K}$ & $298 \mathrm{~K}$ & $373 \mathrm{~K}$ & $423 \mathrm{~K}$ & $473 \mathrm{~K}$ & $523 \mathrm{~K}$ & $573 \mathrm{~K}$ \\
\hline Chemical formula & $\mathrm{Ag}_{5} \mathrm{SbI}_{2} \mathrm{~S}_{3}$ & & & & & & \\
\hline$M / \mathrm{g} \mathrm{mol}^{-1}$ & 1011.098 & & & & & & \\
\hline Space group, $Z$ & Pnnm (No. 58), 4 & & & & & & \\
\hline Crystal size $/ \mathrm{mm}^{3}$ & $0.26 \times 0.18 \times 0.06$ & & & $0.16 \times 0.20 \times 0.31$ & & & \\
\hline Crystal system & Orthorhombic & & & & & & \\
\hline$a / \AA$ & $10.9411(7)$ & $10.9674(8)$ & $11.0033(8)$ & $11.0243(8)$ & $11.0359(8)$ & $11.0602(9)$ & $11.071(1)$ \\
\hline$b / \AA$ & $13.449(1)$ & $13.520(1)$ & $13.569(1)$ & $13.598(1)$ & $13.612(1)$ & $13.656(1)$ & $13.699(1)$ \\
\hline$c / \AA$ & $7.714(1)$ & $7.7392(5)$ & $7.7460(5)$ & $7.7442(5)$ & $7.7424(5)$ & $7.7527(5)$ & $7.7633(6)$ \\
\hline$V / \AA^{3}$ & $1135.1(2)$ & $1147.6(2)$ & $1156.5(2)$ & $1160.9(2)$ & $1163.1(2)$ & $1170.9(2)$ & $1177.4(2)$ \\
\hline$\rho_{\text {calculated }} / \mathrm{g} \mathrm{cm}^{-3}$ & 5.915 & 5.850 & 5.805 & 5.783 & 5.772 & 5.734 & 5.702 \\
\hline$\mu(\mathrm{Mo} \mathrm{K} \alpha) / \mathrm{mm}^{-1}$ & 16.820 & 16.548 & 16.4207 & 16.3583 & 16.3274 & 16.2185 & 16.1291 \\
\hline Diffractometer & IPDS & & & IPDS, X-ray fibre optic & & & \\
\hline Wavelength Mo $\mathrm{K} \alpha / \AA$ & 0.71073 & & & & & & \\
\hline Detector distance $/ \mathrm{mm}$ & 60 & & & 50 & & & \\
\hline$\varphi$-range $/{ }^{\circ}$ & $0 \leqslant \varphi \leqslant 256$ & $0 \leqslant \varphi \leqslant 273$ & $0 \leqslant \varphi \leqslant 330$ & $0 \leqslant \varphi \leqslant 271.5$ & $0 \leqslant \varphi \leqslant 273$ & $0 \leqslant \varphi \leqslant 360$ & $0 \leqslant \varphi \leqslant 360$ \\
\hline$\Delta \varphi /^{\circ}$ & 1.6 & & & 1.5 & & & \\
\hline Number of pictures & 226 & 182 & 220 & 181 & 182 & 240 & 240 \\
\hline Exposure time $/$ min picture $^{-1}$ & 12 & 1.5 & 1.6 & 1.6 & 1.6 & 1.8 & 3.5 \\
\hline Temperature/K & 173 & 298 & 373 & 423 & 473 & 523 & 573 \\
\hline $2 \theta$-range $/{ }^{\circ} \min / \max$ & $4.8 / 56.16$ & $6.06 / 60.84$ & $6.00 / 61.04$ & $6.06 / 60.78$ & $6.42 / 60.82$ & $5.96 / 61.0$ & $6.04 / 60.88$ \\
\hline$h k l$-range & $-14 \leqslant h \leqslant 14$ & & & $-15 \leqslant h \leqslant 15$ & & & \\
\hline & $-17 \leqslant k \leqslant 17$ & & & $-19 \leqslant k \leqslant 19$ & & & \\
\hline & $-10 \leqslant l \leqslant 10$ & & & $-10 \leqslant l \leqslant 10$ & & & \\
\hline Measured reflections & 18882 & 17893 & 21868 & 17982 & 18161 & 24253 & 24368 \\
\hline Independent reflections & 1459 & 1750 & 1778 & 1775 & 1784 & 1814 & 1817 \\
\hline Reflections $I>n \sigma(I) / n$ & $1355 / 3$ & $1278 / 3$ & $1160 / 3$ & $1127 / 2$ & $1090 / 2$ & $1052 / 2$ & $1042 / 2$ \\
\hline Number of parameters & 97 & 149 & 161 & 161 & 161 & 161 & 167 \\
\hline Refinement & Jana98 $8^{17}$ & & & & & & \\
\hline$R_{\text {int }}$ & 0.0282 & 0.0394 & 0.0449 & 0.0519 & 0.0545 & 0.0629 & 0.0581 \\
\hline$R\left(I_{\mathrm{obs}}>n \sigma\left(I_{\mathrm{obs}}\right)\right)$ & 0.0214 & 0.0199 & 0.0236 & 0.0294 & 0.0305 & 0.0329 & 0.0330 \\
\hline $\mathrm{w} R\left(I_{\mathrm{obs}}>n \sigma\left(I_{\mathrm{obs}}\right)\right)$ & 0.0559 & 0.0409 & 0.0503 & 0.0542 & 0.0581 & 0.0633 & 0.0648 \\
\hline$R$ (all) & 0.0241 & 0.0337 & 0.0435 & 0.0560 & 0.0612 & 0.0676 & 0.0686 \\
\hline $\mathrm{w} R$ (all) & 0.0565 & 0.0434 & 0.0536 & 0.0582 & 0.0635 & 0.0678 & 0.0706 \\
\hline Goodness of fit & 2.25 & 1.09 & 1.52 & 1.05 & 1.09 & 1.23 & 1.21 \\
\hline Extinction coefficient & 0 & $0.078(5)$ & $0.104(7)$ & $0.113(5)$ & $0.12(1)$ & $0.11(1)$ & $0.09(1)$ \\
\hline Res. electron density/e $\AA^{-3}$ & $1.06 /-1.20$ & $0.64 /-0.62$ & $0.58 /-0.73$ & $0.69 /-0.67$ & $0.61 /-0.82$ & $1.00 /-0.89$ & $0.62 /-0.57$ \\
\hline
\end{tabular}


$R=0.0273(\mathrm{w} R=0.0420)$ for 149 parameters. Taking a parameter for the secondary extinction into account further improved the refinement.

At $173 \mathrm{~K}$ the silver atoms are more localised than at higher temperatures. Therefore only a split model without a non-harmonic development of the ADPs was used for the crystal structure refinement. With split positions for Ag1, Ag2, Ag3, and $\mathrm{Ag} 4$ and anisotropic ADPs the refinement converged to $R=0.0241$ (w $R=0.0565$ ) for 97 parameters and 1355 independent reflections. A free refinement of the silver occupation factors for the $173 \mathrm{~K}$ data set confirms the value of five silver atoms per formula unit within a $1 \sigma$ level. Therefore the sum of the occupation factors was restricted to the ideal value for five silver atoms per formula unit. In order to get a detailed description of the pronounced delocalisation and to resolve the changes in the silver sublattice an unrestricted refinement of the silver occupation factors was used at $298 \mathrm{~K}$ and higher temperatures. The fractional coordinates for a selected number of data sets are summarized in Table 2, the corresponding anisotropic displacement parameters are given in Table 1S of the electronic supplementary information (ESI). $\ddagger$ Additional information concerning the non-harmonic parameters is provided as supplementary material. The maxima of the probability density, the so-called mode positions, of all nonharmonically refined atoms (datasets $298 \mathrm{~K}$ to $573 \mathrm{~K}$ ) were determined from the probability density functions (pdf) ${ }^{18}$ of the related positions. Mode positions (marked by a d) are not necessarily identical to the positions derived from the least squares refinement when the non-harmonic approach is used.

Table 2 Atomic coordinates and displacement parameters for $(\mathrm{AgI})_{2} \mathrm{Ag}_{3} \mathrm{SbS}_{3}$ at $173 \mathrm{~K}$ and $298 \mathrm{~K}$

\begin{tabular}{|c|c|c|c|c|c|c|}
\hline \multicolumn{7}{|l|}{$173 \mathrm{~K}$} \\
\hline Atom & Position & sof & $x$ & $y$ & $z$ & $U_{\mathrm{eq}}{ }^{a}$ \\
\hline Ag1 & $8 h$ & $0.65(2)$ & $0.2722(1)$ & $0.2308(1)$ & $0.2901(4)$ & $0.0266(3)$ \\
\hline $\mathrm{Ag} 1^{\prime}$ & $8 h$ & 0.35 & $0.2805(4)$ & $0.2398(3)$ & $0.2578(9)$ & $0.050(1)$ \\
\hline Ag2 & $4 g$ & $0.72(1)$ & $0.2131(4)$ & $0.4929(4)$ & 0 & $0.0602(9)$ \\
\hline $\mathrm{Ag} 2^{\prime}$ & $4 g$ & 0.28 & $0.2590(7)$ & $0.5302(4)$ & 0 & $0.0351(9)$ \\
\hline Ag3 & $8 h$ & $0.588(4)$ & $0.00665(9)$ & $0.14515(8)$ & $-0.1333(2)$ & $0.0405(4)$ \\
\hline $\mathrm{Ag} 3^{\prime}$ & $4 g$ & 0.412 & $0.01766(8)$ & $0.87188(8)$ & 0 & $0.0493(7)$ \\
\hline $\mathrm{Ag} 4$ & $8 h$ & $0.586(2)$ & $0.53304(8)$ & $0.4380(1)$ & $0.2749(2)$ & $0.0529(5)$ \\
\hline $\mathrm{Ag} 4^{\prime}$ & $4 e$ & 0.414 & $\frac{1}{2}$ & $x$ & $0.1897(2)$ & $0.0598(5)$ \\
\hline I1 & $4 g$ & 1 & $0.55165(2)$ & $0.29339(2)$ & 0 & $0.02391(8)$ \\
\hline I2 & $4 g$ & 1 & $0.04040(2)$ & $0.64429(1)$ & 0 & $0.02472(8)$ \\
\hline $\mathrm{Sb}$ & $4 g$ & 1 & $0.31671(2)$ & $0.99526(2)$ & 0 & $0.01678(7)$ \\
\hline S1 & $4 g$ & 1 & $0.21057(8)$ & $0.15293(6)$ & 0 & $0.0154(2)$ \\
\hline $\mathrm{S} 2$ & $8 h$ & 1 & $0.30271(5)$ & $0.42204(5)$ & $0.26774(8)$ & $0.0156(2)$ \\
\hline \multicolumn{7}{|l|}{$298 \mathrm{~K}$} \\
\hline Atom $^{b}$ & Position & sof & $x$ & $y$ & $z$ & $U_{\mathrm{eq}}{ }^{a}$ \\
\hline Ag1 & $8 h$ & $0.993(2)$ & $0.2760(1)$ & $0.23711(6)$ & $0.2719(1)$ & $0.0772(5)$ \\
\hline $\mathrm{Ag} 2$ & $4 g$ & $0.75(3)$ & $0.212(2)$ & $0.486(2)$ & 0 & $0.108(4)$ \\
\hline $\mathrm{Ag} 2^{\prime}$ & $4 g$ & $0.24(3)$ & $0.263(1)$ & $0.536(1)$ & 0 & $0.072(2)$ \\
\hline $\mathrm{Ag} 2^{\prime \prime}$ & $4 g$ & $0.023(3)$ & $0.178(3)$ & $0.379(3)$ & 0 & $0.09(2)$ \\
\hline Ag3 & $8 h$ & $0.35(1)$ & $0.006(1)$ & $0.1398(7)$ & $-0.127(3)$ & $0.086(3)$ \\
\hline $\mathrm{Ag} 3^{\prime}$ & $4 g$ & $0.32(2)$ & $0.0204(5)$ & $0.8683(5)$ & 0 & $0.077(4)$ \\
\hline $\mathrm{Ag} 4$ & $8 h$ & $0.37(1)$ & $0.5302(5)$ & $0.446(1)$ & $0.246(1)$ & $0.136(3)$ \\
\hline $\mathrm{Ag} 4^{\prime}$ & $4 e$ & $0.24(6)$ & $\frac{1}{2}$ & $x$ & $0.205(1)$ & $0.087(3)$ \\
\hline I1 & $4 g$ & 1 & $0.55118(3)$ & $0.28970(3)$ & 0 & $0.0426(1)$ \\
\hline I2 & $4 g$ & 1 & $0.04473(3)$ & $0.64370(3)$ & 0 & $0.0442(1)$ \\
\hline $\mathrm{Sb}$ & $4 g$ & 1 & $0.31545(2)$ & $0.99622(2)$ & 0 & $0.02894(9)$ \\
\hline S1 & $4 g$ & 1 & $0.2091(1)$ & $0.15325(8)$ & 0 & $0.0291(3)$ \\
\hline S2 & $8 h$ & 1 & $0.30364(7)$ & $0.42360(6)$ & $0.2681(1)$ & $0.0292(2)$ \\
\hline Agld & $8 h$ & & 0.2733 & 0.2357 & 0.2798 & \\
\hline $\mathrm{Ag} 2 \mathrm{~d}$ & $8 h$ & & 0.211 & 0.4902 & 0 & \\
\hline $\operatorname{Ag} 3 d$ & $8 h$ & & 0.0024 & 0.1445 & -0.1222 & \\
\hline $\mathrm{Ag} 4 \mathrm{~d}$ & $8 h$ & & 0.5313 & 0.443 & 0.2658 & \\
\hline
\end{tabular}

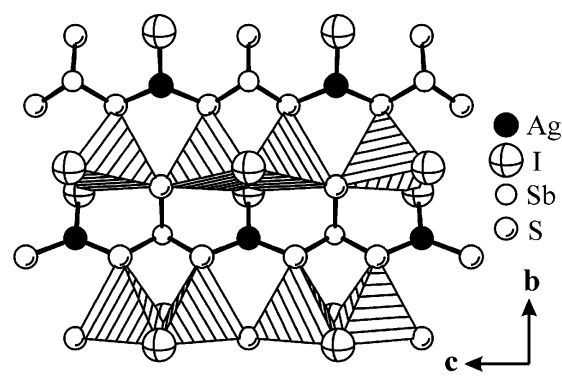

Fig. 1 Polyanionic ${ }_{\infty}^{2}\left[\mathrm{Ag}_{3} \mathrm{SbS}_{3} \mathrm{I}_{2}\right]^{2-}$-layers formed by $\left[\mathrm{SbS}_{3}\right]-$, $\left[\mathrm{AgS}_{2} \mathrm{I}\right]-(\mathrm{Ag} 1)$ and $\left[\mathrm{AgS}_{2} \mathrm{I}_{2}\right]$-units $(\mathrm{Ag} 2) . \mathrm{Ag} 2$ is located inside the dashed tetrahedra.

All distance and angle calculations are based on these mode positions.

\section{Description of the crystal structure}

The crystal structure of $(\mathrm{AgI})_{2} \mathrm{Ag}_{3} \mathrm{SbS}_{3}$ is closely related to that of $(\mathrm{CuI})_{2} \mathrm{Cu}_{3} \mathrm{SbS}_{3}$. Thus, the crystallographic positions of iodine, antimony, and sulfur are almost the same in both compounds. However, at a given temperature the degree of localization of the mobile silver atoms in $(\mathrm{AgI})_{2} \mathrm{Ag}_{3} \mathrm{SbS}_{3}$ and of the corresponding copper atoms in $(\mathrm{CuI})_{2} \mathrm{Cu}_{3} \mathrm{SbS}_{3}$ is different to a certain degree, vide infra. The crystal structure of $(\mathrm{AgI})_{2} \mathrm{Ag}_{3^{-}}$ $\mathrm{SbS}_{3}$ consists of two-dimensional (2D) polyanionic layers ${ }_{\infty}^{2}\left[\mathrm{Ag}_{3} \mathrm{SbS}_{3} \mathrm{I}_{2}\right]^{2-}$ (Fig. 1) which are stacked along [100] (Fig. 2). $\left[\mathrm{SbS}_{3}\right],\left[\mathrm{AgS}_{2} \mathrm{I}\right](\mathrm{Ag} 2)$, and $\left[\mathrm{AgS}_{2} \mathrm{I}_{2}\right](\mathrm{Ag} 1)$ units are located in these layers. Selected distances and bond angles for the essential building units are given in Tables $2 \mathrm{~S}$ and $3 \mathrm{~S}$ of the ESI. The stacking of the layers provides strongly distorted octahedral voids of sulfide ions. Two silver atoms per formula unit

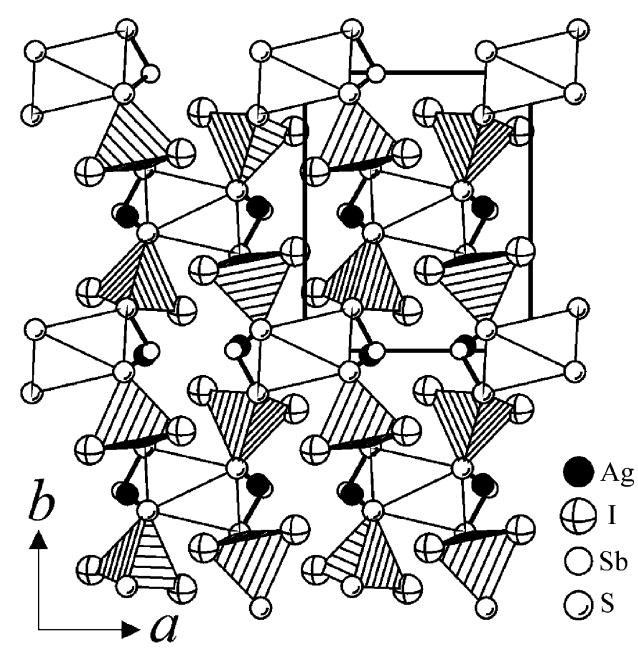

Fig. 2 Projection of the structure along [001]. ${ }_{\infty}^{2}\left[\mathrm{Ag}_{3} \mathrm{SbS}_{3} \mathrm{I}_{2}\right]^{2-}$-layers are stacked along [100]. One unit cell is drawn on top right. Distorted octahedral voids are formed by sulfur of two neighboured $\left[\mathrm{SbS}_{3}\right]$-units. Silver ions located on the octahedral faces are omitted for clarity.

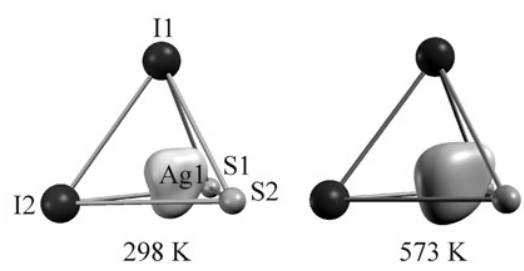

Fig. 3 3D surface plots of the pdf of Ag1 at $298 \mathrm{~K}$ and $573 \mathrm{~K}$. 


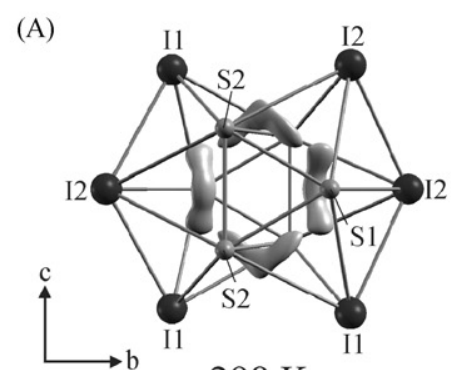

$298 \mathrm{~K}$

(B)
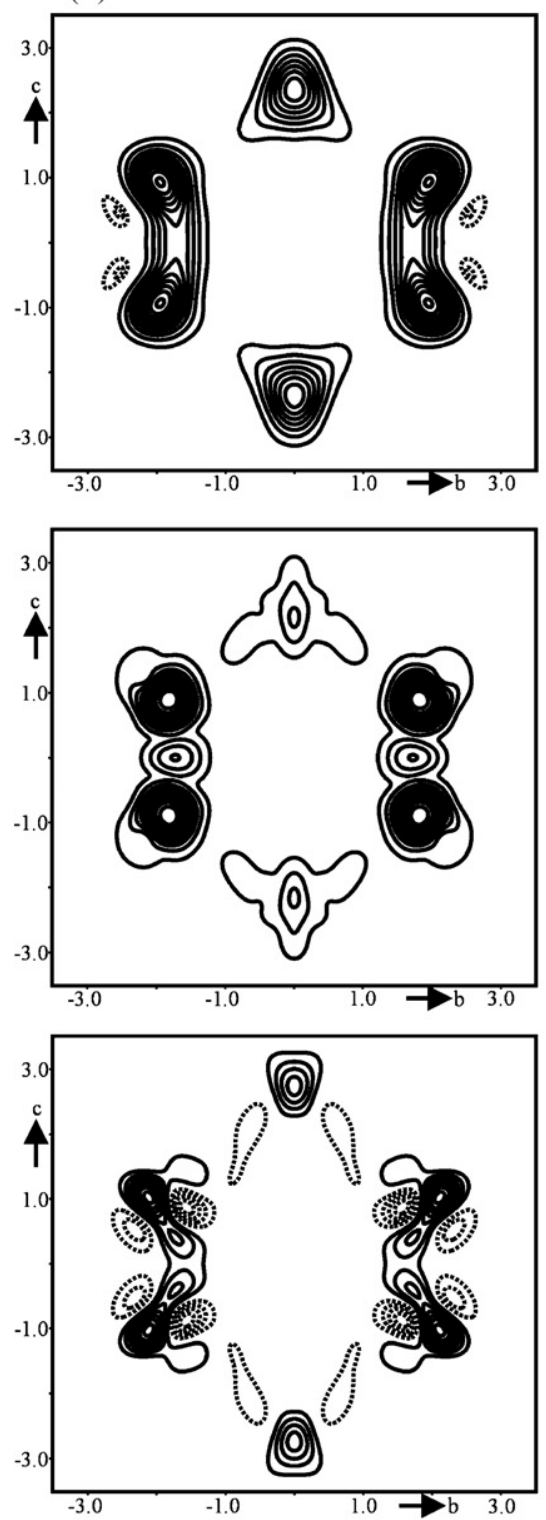

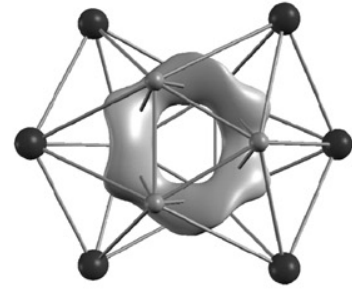

$573 \mathrm{~K}$
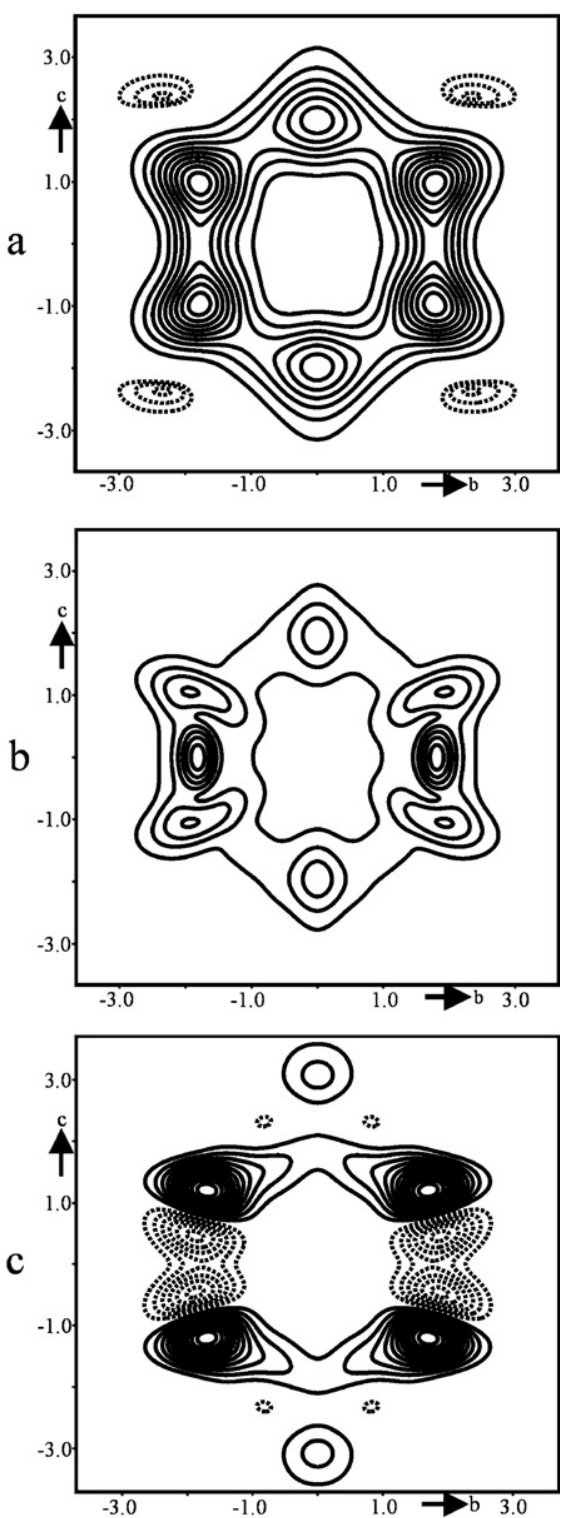

Fig. 4 (A) 3D surface plots of the jpdf of $\mathrm{Ag} 3, \mathrm{Ag} 3^{\prime}, \mathrm{Ag} 4$ and $\mathrm{Ag} 4^{\prime}$ in $(\mathrm{AgI})_{2} \mathrm{Ag}_{3} \mathrm{SbS}_{3}$ at $298 \mathrm{~K}$ and $573 \mathrm{~K}$. A pronounced delocalisation of the silver ions in the HT regime becomes obvious. (B) (a) jpdf of $\mathrm{Ag} 3 / \mathrm{Ag} 3^{\prime}$ and $\mathrm{Ag} 4 / \mathrm{Ag} 4^{\prime}$ at $298 \mathrm{~K}$ and $573 \mathrm{~K}$ (center of the map at (0 00 ), bc-plane). Minimum/maximum density $-0.011 /+1.27 \AA^{-3}$, contour lines $-0.005 /+0.125 \AA^{-3}(298 \mathrm{~K}) ;-0.0016 /+0.50 \AA^{-3}$, contour lines $-0.0005 /+0.05$ $\AA^{-3}$. (b) error map of $\mathrm{Ag} 3 / \mathrm{Ag} 3^{\prime}$ and $\mathrm{Ag} 4 / \mathrm{Ag} 4^{\prime}$ at $298 \mathrm{~K}$ and $573 \mathrm{~K}$. Max $+0.07 \AA^{-3}$, contour lines $+0.007 \AA^{-3}(298 \mathrm{~K})$; Max $+0.034 \AA^{-3}$, contour

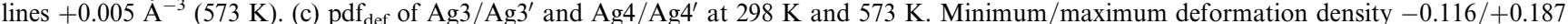
$\AA^{-3}$, contour lines $\pm 0.025 \AA^{-3}(298 \mathrm{~K})$; Minimum/maximum deformation density $-0.12 /+0.06 \AA^{-3}$, contour lines $\pm 0.01 \AA^{-3}$ (573 K).

(Ag3, Ag4) are distributed on the triangular faces of these octahedra, but no electron density corresponding to silver is located inside these voids.

The single polyanionic layers ${ }_{\infty}^{2}\left[\mathrm{Ag}_{3} \mathrm{SbS}_{3} \mathrm{I}_{2}\right]^{2-}$ consist of trigonal coordinated $\mathrm{Sb}$ and $\mathrm{Ag}$ atoms alternating along [001]. The coordination polyhedra $\left[\mathrm{SbS}_{3}\right]$ and $\left[\mathrm{AgS}_{2} \mathrm{I}\right]$ share common sulfur atoms. Taking distances $d(\mathrm{Ag}-\mathrm{I})>3 \AA$ into account
Ag2 has a $3+1$ coordination. In addition four-coordinate $\mathrm{Ag}$ atoms form a parallel strand of polyhedra. This second strand in the layers exhibits pairs of tetraheda $\left[\mathrm{AgS}_{2} \mathrm{I}_{2}\right]$ which share common edges formed by the iodine atoms. These double-tetrahedra are linked to neighbouring double-tetrahedra via the sulfur atoms. Two additional $\mathrm{Ag}^{+}$ions are needed to compensate the charge of the layers. They are disordered on those six 

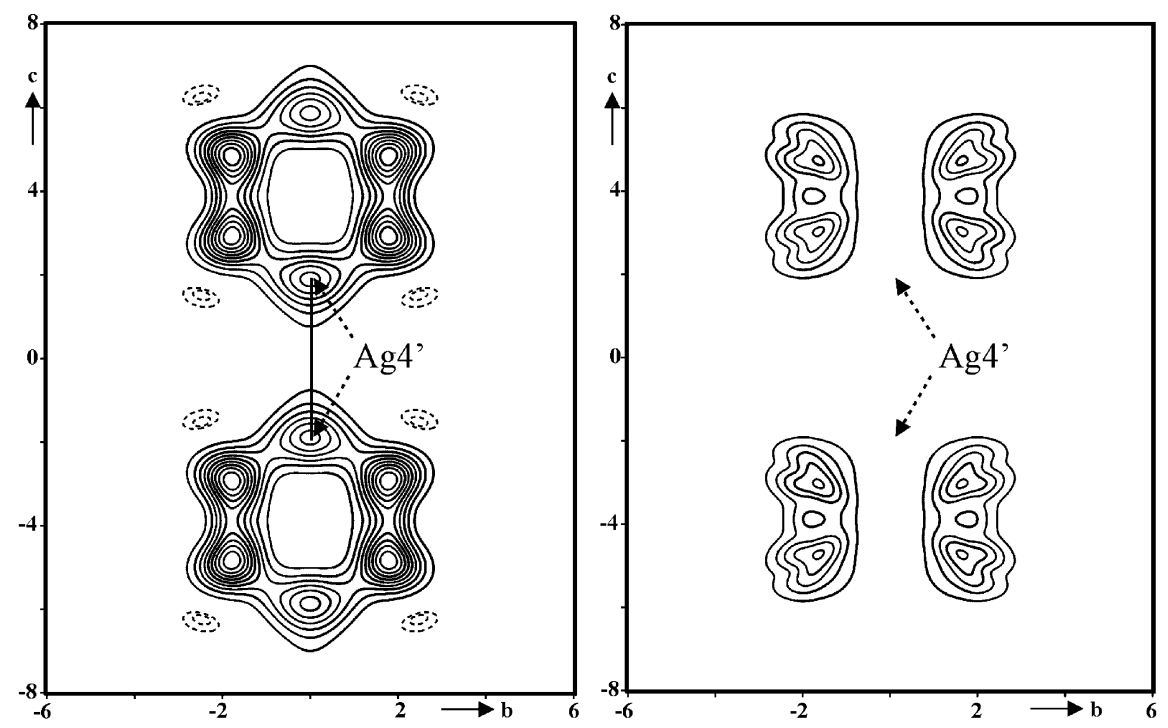

Fig. 5 Left: jpdf map of two sets of Ag3/Ag3 ${ }^{\prime}$ and $\mathrm{Ag} 4 / \mathrm{Ag} 4^{\prime}$-positions in the $b c$-plane at $573 \mathrm{~K}$. The line indicates the diffusion pathway between two Ag4'-positions. Minimum/maximum density of the jpdf $-0.001 /+0.49 \AA^{-3}$, contour lines $-0.0005 /+0.03 \AA^{-3}$. Right: Error map of the $\mathrm{Ag} 3 / \mathrm{Ag} 3^{\prime}$ and $\mathrm{Ag} 4 / \mathrm{Ag} 4^{\prime}$ positions. Maximum error $+0.026 \AA^{-3}$, contour lines $+0.005 \AA^{-3}$.

faces of the sulfur octahedra which are more or less perpendicular to (010). The remaining two faces of the octahedra which are parallel (010) are capped by $\mathrm{Sb}$ atoms.

\section{Distribution of the silver atoms}

The refinement of the crystal structure of $(\mathrm{AgI})_{2} \mathrm{Ag}_{3} \mathrm{SbS}_{3}$ at RT using the conventional (harmonic) approach resulted in relatively large ADPs combined with the necessity to use several close split positions. Strong correlations for the parameters of the silver atoms were observed due to the short distances between the not fully occupied positions. In addition, the refinement did not provide a satisfactory $R$ value, vide supra. This finding is typical for fast ionic conductors with a large number of energetically almost equal positions for the mobile ions. Therefore a Gram-Charlier development of the ADPs of the silver atoms up to the third order was used in the final refinement stages. However, the best results were obtained when both the non-harmonic refinement and in addition two split positions $\mathrm{Ag} 2$ and one split position at $\mathrm{Ag} 3$ and $\mathrm{Ag} 4$ (denoted as $\mathrm{Ag} n^{\prime}$ and $\mathrm{Ag} n^{\prime \prime}, n=2-4$ in Table 2) were applied. The resulting probability density function (pdf) plots and in the case of overlapping pdfs the joint probability density function (jpdf) plots for the silver atoms are shown in Figs. 3, 1S and 4(A). To prove the significance of the pdf the non-harmonic deformation densities $\operatorname{pdf}_{\text {def }}{ }^{18}$ and the errors of the $\mathrm{pdf}^{19}$ were calculated for all sections under discussion. An example is given in Fig. 4(B). The jpdfs are considered to be significant when they are much higher than the calculated errors. Also no pronounced negative regions must to be observed, i.e. they must be within the estimated error. A detailed description of the non-harmonic approach is given elsewhere. ${ }^{6}$ The comparison of the jpdf at room temperature and $573 \mathrm{~K}$ leads to the conclusion that a high mobility of silver ions occurs in the title compound especially at elevated temperatures.

\section{Diffusion pathways in $(\mathrm{AgI})_{2} \mathrm{Ag}_{3} \mathrm{SbS}_{3}$}

Preferred pathways for the mobile silver atoms can be estimated from the shape of the related jpdf. In addition, a quantitative analysis of effective one-particle potentials (opp) between neighbouring silver positions is highly desirable in order to determine the barriers between different positions in the crystal structure. Opps can be derived from the related jpdf. ${ }^{18,20}$ However, in case of the title compound the silver positions are far from full occupancies and therefore no physical meaningful potentials can be calculated from the jpdf. Thus, no quantitative data will be given here.

Due to the structural features in $(\mathrm{AgI})_{2} \mathrm{Ag}_{3} \mathrm{SbS}_{3}$ a $2 \mathrm{D}$ transport of silver parallel to the polyanionic ${ }_{\infty}^{2}\left[\mathrm{Ag}_{3} \mathrm{SbS}_{3} \mathrm{I}_{2}\right]^{2-}$ layers as well as a $3 \mathrm{D}$ transport has to be considered. A pronounced smearing of the jpdf can be observed between $\mathrm{Ag} 3 / \mathrm{Ag} 3^{\prime}$ and $\mathrm{Ag} 4 / \mathrm{Ag}^{\prime}$ located on the surface of the distorted $\mathrm{S}_{6}$-octaheda which connect two polyanionic ${ }_{\infty}^{2}\left[\mathrm{Ag}_{3} \mathrm{SbS}_{3} \mathrm{I}_{2}\right]^{2-}$ layers (Fig. 4(A)). The jpdf of the corresponding silver atoms broadens significantly and in addition the occupation factors change for the different postions when the temperature increases from $173 \mathrm{~K}$ to $573 \mathrm{~K}$. One can expect a high mobility between the discussed silver positions. One possible 2D path connects two sets of $\mathrm{Ag} 3$ and $\mathrm{Ag} 4$ positions shaped like a "silver ring" located in the $b c$-plane of $(\mathrm{AgI})_{2} \mathrm{Ag}_{3} \mathrm{SbS}_{3}$ (Fig. 5). Because of the interaction with neighboured iodine atoms a slightly bent diffusion pathway is favoured against a direct jump (Fig. 6). An alternative 2D pathway involves the $\mathrm{Ag} 4$ position of the silver ring and the $\mathrm{Ag} 2^{\prime}$ position localised in the polyanionic ${ }_{\infty}^{2}\left[\mathrm{Ag}_{3} \mathrm{SbS}_{3} \mathrm{I}_{2}\right]^{2-}$ layer. Jpdf maps at different temperatures illustrate the evolution of a diffusion pathway between these two positions (Fig. 7). A second 2D pathway has to be taken into account within the polyanionic ${ }_{\infty}^{2}\left[\mathrm{Ag}_{3} \mathrm{SbS}_{3} \mathrm{I}_{2}\right]^{2-}$ layer itself. This pathway incorporates the $\mathrm{Ag} 2^{\prime}, \mathrm{Ag} 1$, and

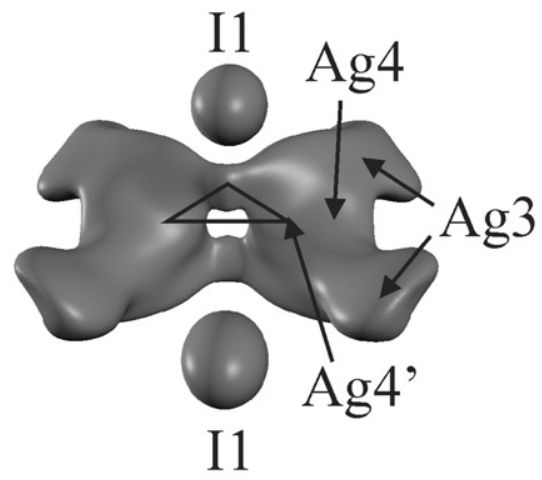

Fig. 6 Slightly bent diffusion pathway between adjacent $\mathrm{Ag} 4^{\prime}$ positions caused by interaction of neighbouring iodide ions. 

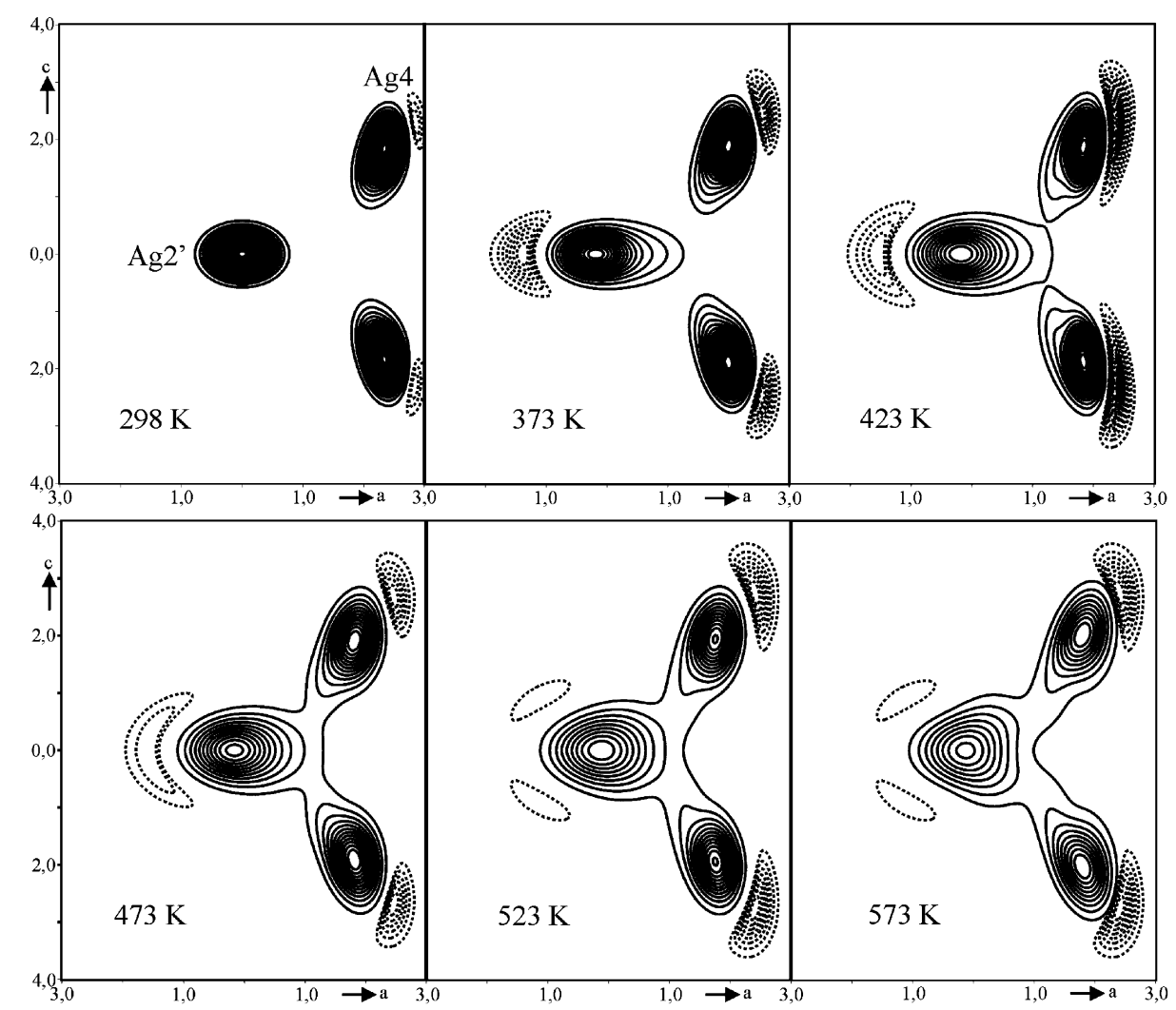

Fig. 7 Temperature dependent evolution of the jpdf maps of $\mathrm{Ag} 4$ and $\mathrm{Ag} 2^{\prime}$ in the ac-plane of $\left(\mathrm{AgI}_{2} \mathrm{Ag}_{3} \mathrm{SbS}_{3}\right.$. Minimum/maximum density: $-0.004 /+1.05 \AA^{-3}(298 \mathrm{~K}),-0.009 /+0.63 \AA^{-3}(373 \mathrm{~K}),-0.017 / 0.53 \AA^{-3}(423 \mathrm{~K}),-0.007 /+0.38 \AA^{-3}(473 \mathrm{~K}),-0.009 /+0.37 \AA^{-3}(523 \mathrm{~K})$, $-0.007 /+0.30 \AA^{-3}(573 \mathrm{~K})$. Contour lines $-0.001 / 0.03 \AA^{-3}$.

$\mathrm{Ag} 2^{\prime \prime} / \mathrm{Ag} 2$ positions. However, the jpdfs for these positions do not show a similar smearing out as the one shown in Fig. 7. Therefore a $2 \mathrm{D}$ transport involving the polyanionic ${ }_{\infty}^{2}\left[\mathrm{Ag}_{3} \mathrm{SbS}_{3} \mathrm{I}_{2}\right]^{2-}$ layer seems less favourable. It is concluded that $3 \mathrm{D}$ transport parallel and perpendicular to the polyanionic ${ }_{\infty}^{2}\left[\mathrm{Ag}_{3} \mathrm{SbS}_{3} \mathrm{I}_{2}\right]^{2-}$ layers is less probable than $2 \mathrm{D}$ transport in the $b c$-plane involving the silver ring and the $\mathrm{Ag} 2^{\prime}$ position.

\section{Ionic conductivity measurements}

A high ionic conductivity can be expected for $(\mathrm{AgI})_{2} \mathrm{Ag}_{3} \mathrm{SbS}_{3}$ because of the pronounced non-harmonic behaviour of silver in this material. Impedance spectroscopic measurements on powdered samples using a blocking electrode setup were performed to prove this assumption. AC impedance measurements in the region from $332 \mathrm{~K}$ to $479 \mathrm{~K}$ result in typical plots with semicircles at high frequencies and a linear spike at low frequencies. Selected ionic conductivities are $8.15 \times$ $10^{-5} \Omega^{-1} \mathrm{~cm}^{-1}(332 \mathrm{~K})$ and $1.52 \times 10^{-3} \Omega^{-1} \mathrm{~cm}^{-1}$ (478 K). Fig. 8 illustrates the temperature dependent ionic conductivities

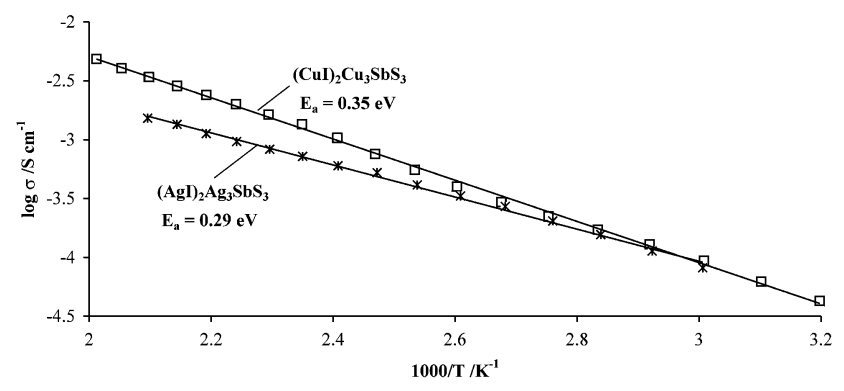

Fig. 8 Comparison of the ionic conductivity of $(\mathrm{CuI})_{2} \mathrm{Cu}_{3} \mathrm{SbS}_{3}$ (ref. 6) and $(\mathrm{AgI})_{2} \mathrm{Ag}_{3} \mathrm{SbS}_{3}$. of $(\mathrm{AgI})_{2} \mathrm{Ag}_{3} \mathrm{SbS}_{3}$ and the isotypic $(\mathrm{CuI})_{2} \mathrm{Cu}_{3} \mathrm{SbS}_{3}$. In the HT regime the ionic conductivity of $(\mathrm{AgI})_{2} \mathrm{Ag}_{3} \mathrm{SbS}_{3}$ is slightly lower than that of $(\mathrm{CuI})_{2} \mathrm{Cu}_{3} \mathrm{SbS}_{3}$ whereas the activation energy decreases to a certain degree from the copper to the silver compound from $0.35 \mathrm{eV}$ to $0.29 \mathrm{eV}$. Thus, these two homologous compounds have a very similar ionic conductivity. This is in contrast to the ionic conductors $\mathrm{KCu}_{4} \mathrm{I}_{5}\left(\mathrm{ca} .10^{-6} \Omega^{-1}\right.$ $\mathrm{cm}^{-1}$ at $\left.373 \mathrm{~K}\right)$ and $\mathrm{KAg}_{4} \mathrm{I}_{5}\left(\mathrm{ca} \cdot 10^{-1} \Omega^{-1} \mathrm{~cm}^{-1}\right.$ at $\left.373 \mathrm{~K}\right){ }^{21}$ $\alpha$-CuI $\left(9.0 \times 10^{-2} \Omega^{-1} \mathrm{~cm}^{-1} \text { at } 723 \mathrm{~K}\right)^{22}$ and $\alpha$-AgI $\left(10^{1} \Omega^{-1}\right.$ $\mathrm{cm}^{-1}$ at $\left.423 \mathrm{~K}\right),{ }^{22}$ and $\mathrm{Cu}_{2} \mathrm{HgI}_{4}$ and $\mathrm{Ag}_{2} \mathrm{HgI}_{4} \cdot{ }^{23}$ Usually the silver compounds are the better ionic conductors. Such structural aspects as the number of free interstitial positions and repulsive interactions between the mobile ions seem to be more dominant in case of the title compound.

The morphology of the crystals (plates) leads to oriented powdered samples with a preferred orientation of the crystals in the impedance experiment. This orientation leads to an activation energy with a more pronounced contribution of the conduction parallel the crystallographic $a$ axis (perpendicular to the plane). Therefore the activation energy determined by impedance spectroscopy is close to the values parallel to the $a$ axis. The ionic conductivity of $(\mathrm{AgI})_{2} \mathrm{Ag}_{3} \mathrm{SbS}_{3}$ is supposed to be anisotropic with a higher conductivity in the $b c$-plane. Single crystal measurements on large crystals were necessary to further prove this assumption.

\section{Raman spectroscopy}

Raman spectroscopic measurements on $\mathrm{Cu}_{3} \mathrm{SbS}_{3}$ and $(\mathrm{CuI})_{2}$ $\mathrm{Cu}_{3} \mathrm{SbS}_{3}$ recently showed that the $\left[\mathrm{SbS}_{3}\right]^{3-}$ units in $(\mathrm{CuI})_{2}-$ $\mathrm{Cu}_{3} \mathrm{SbS}_{3}$ can be regarded as isolated from the surrounding copper(I) halide matrix. ${ }^{6}$ The question arises whether this finding can be transferred from copper(I) compounds to homologous silver(I) compounds.

In case of the $C_{3 \mathrm{v}}$ symmetrical $\left[\mathrm{SbS}_{3}\right]^{3-}$ unit in $\mathrm{Ag}_{3} \mathrm{SbS}_{3}$ two stretching modes $\left(\nu_{1}\left(\mathrm{~A}_{1}\right)\right.$ and $\left.\nu_{3}(\mathrm{E})\right)$ can be expected. ${ }^{9}$ 


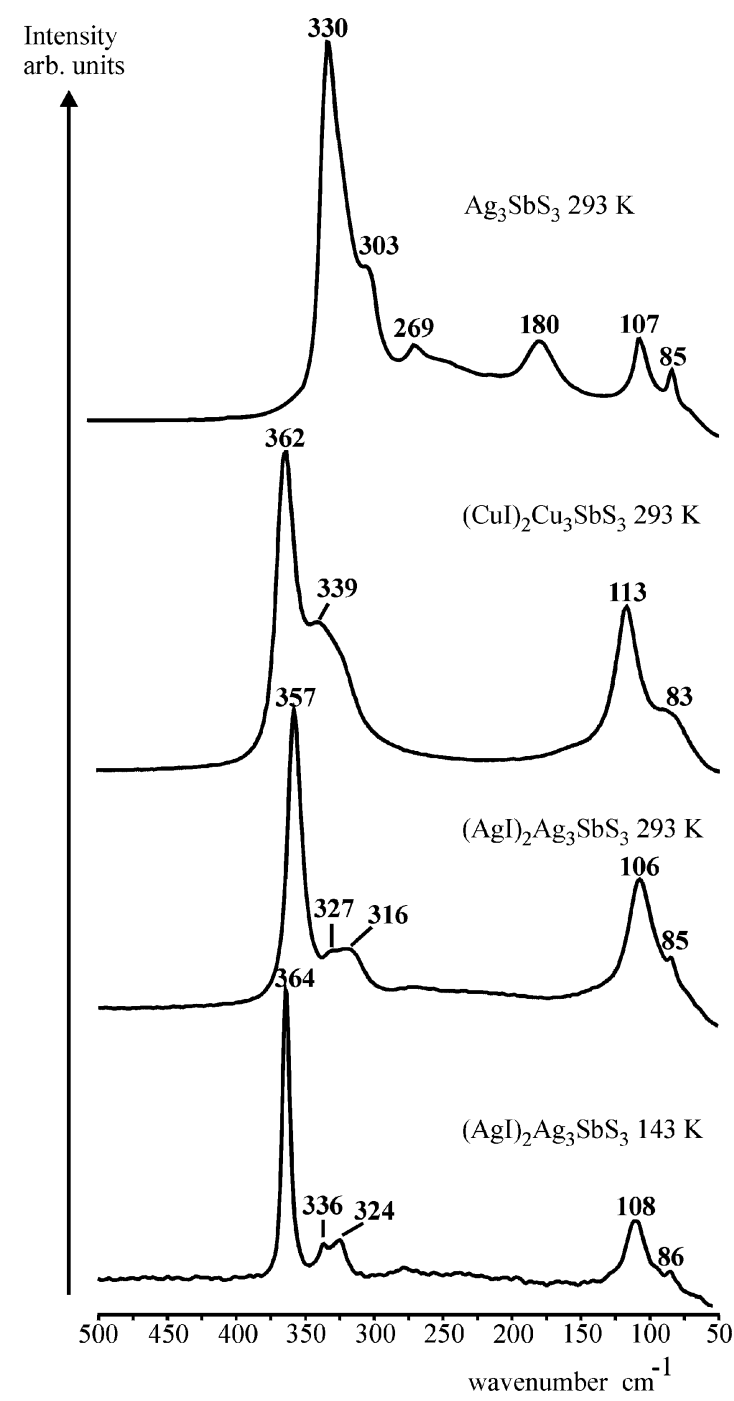

Fig. 9 Raman spectra of $\mathrm{Ag}_{3} \mathrm{SbS}_{3},(\mathrm{CuI})_{2} \mathrm{Cu}_{3} \mathrm{SbS}_{3}$ (ref. 6) and $(\mathrm{AgI})_{2} \mathrm{Ag}_{3} \mathrm{SbS}_{3}$. Secondary interactions between sulfur and antimony in $\mathrm{Ag}_{3} \mathrm{SbS}_{3}$ leads to a shift of the $\left[\mathrm{SbS}_{3}\right]$ stretching bands between $370 \mathrm{~cm}^{-1}$ and $300 \mathrm{~cm}^{-1}$ compared to the copper and silver adduct compounds. The symmetry reduction of the $\left[\mathrm{SbS}_{3}\right]$ units from $C_{3 \mathrm{v}}\left(\mathrm{Ag}_{3} \mathrm{SbS}_{3}\right)$ to $C_{\mathrm{s}}\left((\mathrm{CuI})_{2} \mathrm{Cu}_{3} \mathrm{SbS}_{3}\right.$ and $\left.\left.(\mathrm{AgI})_{2} \mathrm{Ag}_{3} \mathrm{SbS}_{3}\right)\right)$ leads to a splitting of one stretching mode. The splitting is resolved at low temperatures.

Lowering of the symmetry to $C_{\mathrm{s}}$ leads to a split of the $\nu_{3}(\mathrm{E})-$ mode into a symmetrical $\mathrm{A}^{\prime}$ and an asymmetrical $\mathrm{A}^{\prime \prime}$ mode (Fig. $3 \mathrm{~S}$ in the ESI) $\ddagger$ The two stretching bands of the $\left[\mathrm{SbS}_{3}\right]^{3-}$ unit of $\mathrm{Ag}_{3} \mathrm{SbS}_{3}$ are located at $330 \mathrm{~cm}^{-1}$ and at $303 \mathrm{~cm}^{-1}$. The Raman spectrum of $(\mathrm{AgI})_{2} \mathrm{Ag}_{3} \mathrm{SbS}_{3}$ is dominated by strong bands at $357 \mathrm{~cm}^{-1}, 327 \mathrm{~cm}^{-1}$, and at $316 \mathrm{~cm}^{-1}$ (see Fig. 9). The strong red-shift of about $30 \mathrm{~cm}^{-1}$ in the spectrum of $\mathrm{Ag}_{3} \mathrm{SbS}_{3}$ is due to a secondary interaction of sulfur and antimony in $\mathrm{Ag}_{3} \mathrm{SbS}_{3}$ as discussed earlier. ${ }^{6}$ The most important fact is that there is no significant shift of the stretching bands of the $\left[\mathrm{SbS}_{3}\right]^{3-}$ unit in $(\mathrm{AgI})_{2} \mathrm{Ag}_{3} \mathrm{SbS}_{3}$ and $(\mathrm{CuI})_{2} \mathrm{Cu}_{3} \mathrm{SbS}_{3}$. Thus, it can be concluded that the $\left[\mathrm{SbS}_{3}\right]^{3-}$ units are isolated from each other and no so-called non-bonding interactions between antimony and sulfur occur. The concept of using copper(I) halides as a preparative tool is successfully transferred to silver(I) halides.

\section{Conclusion}

$(\mathrm{AgI})_{2} \mathrm{Ag}_{3} \mathrm{SbS}_{3}$ is the first example of an adduct compound of a silver(I) halide and thiometallate anions. Raman spectroscopic measurements, especially the similarities concerning the positions of the stretching modes between $(\mathrm{AgI})_{2} \mathrm{Ag}_{3} \mathrm{SbS}_{3}$ and $(\mathrm{CuI})_{2} \mathrm{Cu}_{3} \mathrm{SbS}_{3}$, prove the isolated character of the $\left[\mathrm{SbS}_{3}\right]^{3-}$ units. In contrast to many other silver ion conductors $(\mathrm{AgI})_{2} \mathrm{Ag}_{3} \mathrm{SbS}_{3}$ shows no phase transition between $173 \mathrm{~K}$ and the melting point at $720 \mathrm{~K}$. The ionic conductivity around room temperature is remarkable high as compared to the conductivity of pure AgI. X-ray structure investigations reveal a pronounced temperature dependent disorder of the silver atoms. The best description of the structure could be obtained using a Gram-Charlier development of the ADPs of the silver atoms. The most favourable conduction path could be derived from the analysis of the jpdfs. An anisotropic ionic conductivity with a favored 2D transport within the $b c$-plane results. $(\mathrm{AgI})_{2} \mathrm{Ag}_{3} \mathrm{SbS}_{3}$ is stable against light and air for several months in contrast to $\mathrm{RbAg}_{4} \mathrm{I}_{5}$ for instance. The properties of this new silver ion conductor open a wide field to low temperature ionic conductors, especially when a high stability in a wide temperature range is necessary. However, it has to be stated that especially $\mathrm{RbAg}_{4} \mathrm{I}_{5}$ has a much higher conductivity than the title compound.

\section{Acknowledgements}

The authors thank Prof. Deiseroth for his continuous support and Prof. Haeuseler and Regina Stötzel for recording Raman spectra. J.H.H. gratefully acknowledges a stipend from OhSung Polytechnology Ind. This work was financially supported by the Deutsche Forschungsgemeinschaft (DFG) and the Fonds der Chemischen Industrie (FCI).

\section{References}

1 A. Pfitzner and E. Freudenthaler, Angew. Chem., 1995, 107, 1784; Angew. Chem., Int. Ed. Engl., 1995, 34, 1647.

2 R. Bachmann, K. D. Kreuer, A. Rabenau and H. Schulz, Acto Crystallogr., Sect. B, 1982, B38, 2361.

3 E. Freudenthaler and A. Pfitzner, Solid State Ionics, 1997, 101-103, 1053

4 E. Freudenthaler, A. Pfitzner and D. C. Sinclair, Mater. Res. Bull., 1996, 31(2), 171.

5 A. Pfitzner, Chem. Eur. J., 2000, 6, 1891.

6 A. Pfitzner, Chem. Eur. J., 1997, 3, 2032.

7 A. Pfitzner and S. Zimmerer, Angew. Chem., 1997, 109, 1031; Angew. Chem., Int. Ed. Engl., 1997, 36, 982.

8 A. Pfitzner, S. Reiser, T. Nilges and W. Kockelmann, J. Solid State Chem., 1999, 147, 170.

9 A. Pfitzner, Inorg. Chem., 1998, 37, 5164

10 B. Reuter and K. Hardel, Naturwissenschaften, 1961, 48, 161; E. Perenthaler, H. Schulz and H. U. Beyeler, Acta Crystallogr., Sect. B, 1981, B37, 1017; J.-J. Didisheim, R. K. Mc Mullan and B. J. Wuensch, Solid State Ionics, 1986, 18-19, 1150.

11 B. Reuter and K. Hardel, Z. Anorg. Allg. Chem., 1965, 340, 168.

12 A. Nagel and K. Range, Z. Naturforsch., Sect. B, 1979, 34, 360; B. Cros, M. Lagibi, S. Peytavin and M. Ribes, Rev. Chim. Mineral., 1986, 86, 796.

13 K. J. Range and H. J. Hübner, Z. Naturforsch., Sect. B, 1983, 38, 155.

14 R. Blachnik and H. A. Dreisbach, J. Solid State Chem., 1985, 60, 115.

15 T. Doert, E. Ronsch, P. Böttcher and J. Sieler, Z. Anorg. Allg. Chem., 2000, 626, 89.

$16 X$-SHAPE, STOE, Darmstadt, Germany, 1996.

17 V. Petricek and M. Dusek, JANA98, Program for Structure Refinement, Institute of Physics, Academy of Czech Republic, Prague, 1998.

18 W. F. Kuhs, Acta Crystallogr., Sect. A, 1992, A48, 80.

19 A. Pfitzner, M. Evain and V. Petricek, Acta Crystallogr., Sect. B, 1997, B53, 337.

20 R. Bachmann and H. Schulz, Acta Crystallogr., Sect. A, 1984, A40, 668.

21 T. Matsui and J. B. Wagner Jr., J. Electrochem. Soc., 1977, 124(6), 937.

22 R. C. Agrawal and R. K. Gupta, J. Mater. Sci., 1999, 34, 1131, and references therein.

23 L. Suchow and G. R. Pond, J. Am. Chem. Soc., 1953, 75, 5242. 